\title{
CONGENITAL ANEURYSM OF THE CORONARY ARTERY*
}

BY

\author{
M. GROB and E. KOLB \\ From the Surgical Department of the Children's Hospital, Zurich, Switzerland
}

As compared with the totality of congenital malformations of the heart, anomalies of the coronary vessels are relatively rare. In the literature, anomalous origin of these vessels has been taken adequately into account. Less emphasis has been laid, however, on conditions such as congenital aneurysms of the coronary arteries which probably occur more frequently than is commonly believed.

The following two cases observed by us will illustrate this anomaly.

\section{Case Histories}

Case 1. She was a $7 \frac{1}{2}$-year-old girl, whose medical history indicated that a murmur over the heart had been

* A paper read at a meeting of the British Association of Paediatric Surgeons held in London in July, 1958.

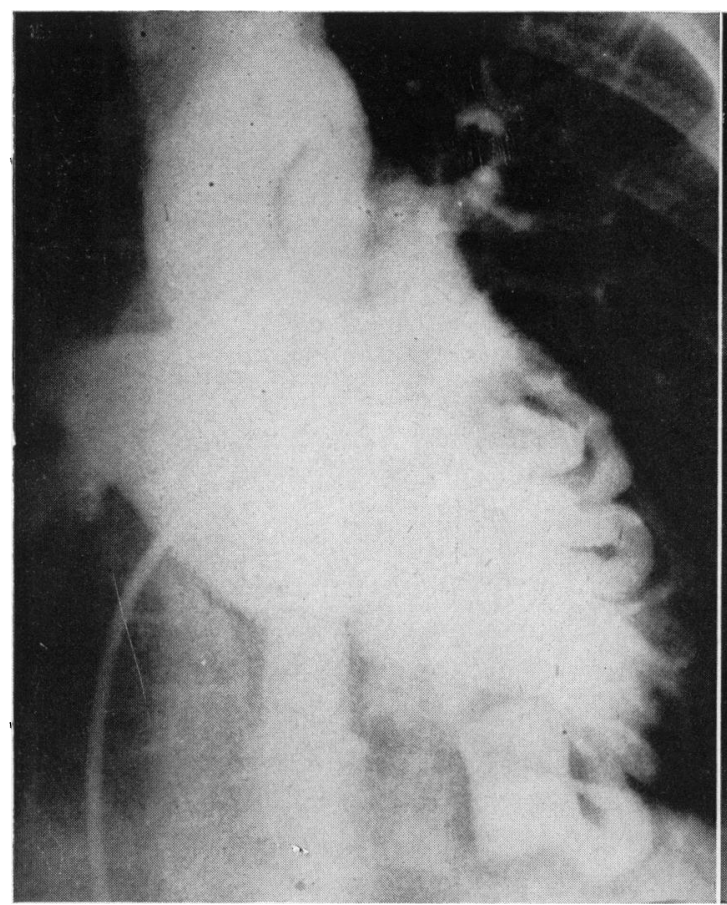

Fig. 1-Case 1. Frontal angiocardiogram showing a tortuous vessel on the left side of the heart, ending in a saccular structure below the left ventricle. noted since the age of 4 weeks. Her physical development and functional capacity, however, had been normal. She was referred to our hospital for suspected patent ductus. Physical examination revealed a loud continuous murmur, with maximum intensity in the fourth left intercostal space immediately near the apex. Roentgenograms of the thorax, electrocardiographic tracings and blood pressure readings were normal. Cardiac catheterization disclosed right heart pressures and oxygen saturation within normal limits. A patent foramen ovale was catheterized, but seemed to be without a haemodynamic significance. Angiocardiography revealed a tortuous dilated vessel on the left side of the heart, ending in a cherry-sized structure below the left ventricle (Figs. 1 and 2). These findings were easily seen to represent an aneurysmal deformation of the left coronary artery which was responsible for the continuous

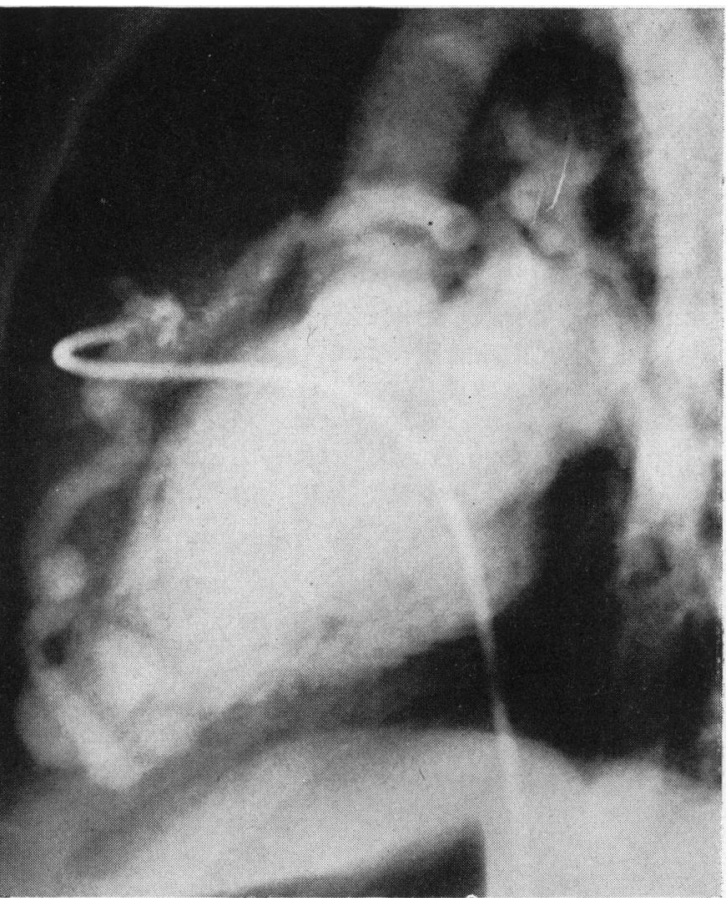

FIG. 2.-Lateral angiocardiogram. The markedly dilated left coronary artery runs down in numerous coils towards the apex and enters the aneurysm. 


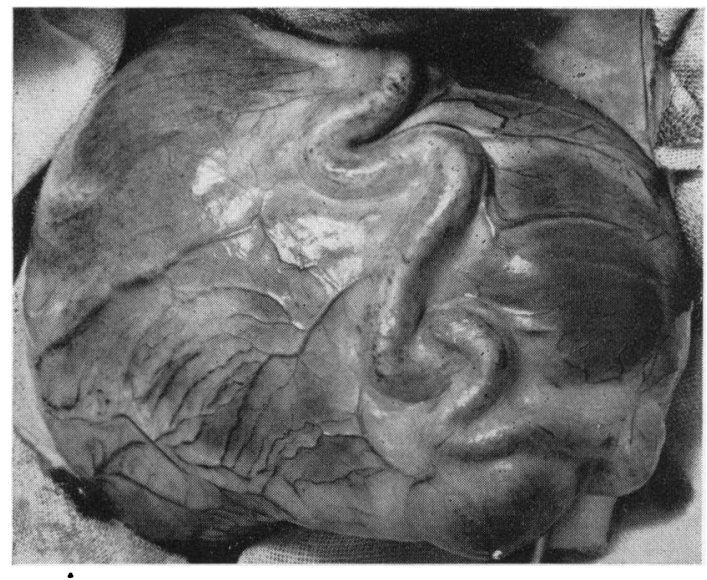

FIG. 3.-Case 1. Anterior view of the heart at operation. Serpentine dilatation of the left coronary artery. Aneurysm at the apex. murmur. Rupture is known to occur in such aneurysms, and because of this and because the localization of the aneurysm near the apex was favourable, we decided to operate.

After a bilateral anterior incision of the thoracic wall the pericardium was opened and the condition previously mentioned was confirmed. The left coronary artery was enormously dilated down its whole course to the apex, where it turned to the right and entered a saccular aneurysm situated at the lower border of the right ventricle (Fig. 3). The dilatation involved the main stem only and not the branches. On the saccular portion of the dilated vessel a continuous thrill was palpable that disappeared after temporary clamping of the coronary artery. Since there were no signs of myocardial ischaemia at the apex due to this procedure, the coronary artery was doubly ligated at its point of entrance into the aneurysm. The previously distended sac could now easily be pressed in by the finger, but it slowly filled up again from the back. This was thought to be caused by

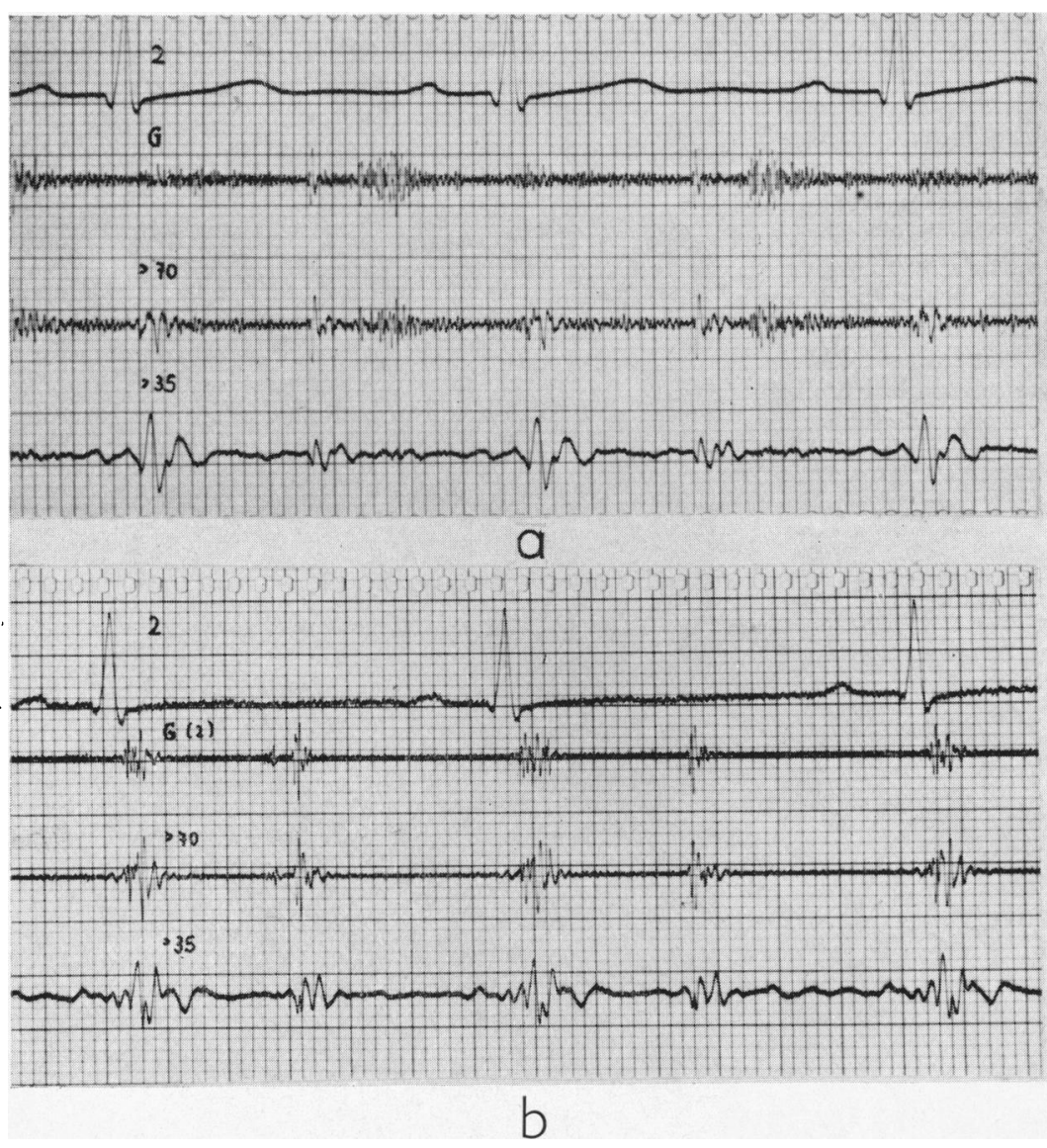

FIG. 4.-Case 1. Phonocardiographic tracings: (a) before operation: continuous murmur; $(b)$ after operation: disappearance of continuous murmur

Fig. 5.-Case 1. Seven-and-a-half-year-old girl operated on for aneurysm of the left coronary artery.

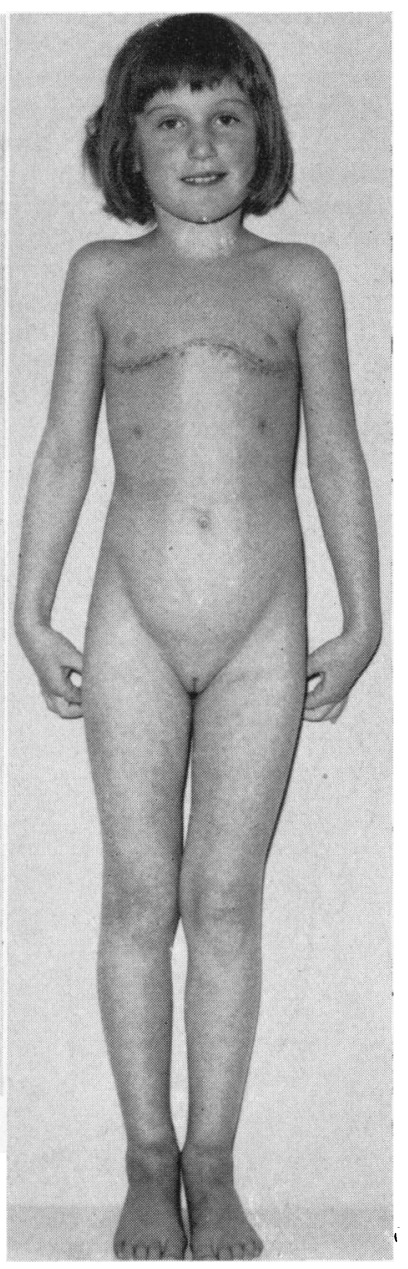


a communication with the right ventricle, although angiocardiography failed to demonstrate this with certainty. Instead of resecting the thin-walled sac, we decided to invaginate it and to suture the margins obliquely with a row of interrupted silk sutures. The post-operative course was uneventful. Before the patient's discharge from hospital the continuous murmur could no longer be heard or demonstrated by phonocardiographic tracings (Fig. 4) and her condition was satisfactory (Fig. 5).

Case 2. A 14-year-old boy was referred to hospital owing to a precordial murmur apparent since the age of 1 year, on the basis of which a patent ductus had been assumed. His growth and development had been normal. In the last few years exercise tolerance seemed to have slightly decreased. Cyanosis and dyspnoea at rest were always absent. Physical examination revealed a continuous murmur over the heart the maximal intensity of which was located in the third intercostal space at the right sternal border. Right heart catheterization showed increased oxygen saturation of $89 \%$ in the right ventricle. Contrast visualization of the cardiac chambers performed by injection of Ioduron $70 \%$ into the right ventricle failed to reveal the lesion with clarity.

At probatory thoracotomy an obliterated Botallo's ligament was encountered. Over the heart, however, a harsh thrill was palpable which at first suggested arteriopulmonary fistula. After incision of the pericardium we ascertained that the continuous thrill was not located in the pulmonary artery, but in an aneurysm of the right coronary artery situated immediately below the origin of this vessel. Furthermore, the left coronary artery was also anomalous, showing diffuse serpentine dilatation (Figs. 6 and 7). In view of these anatomical findings ligation of the aneurysm was not deemed advisable.

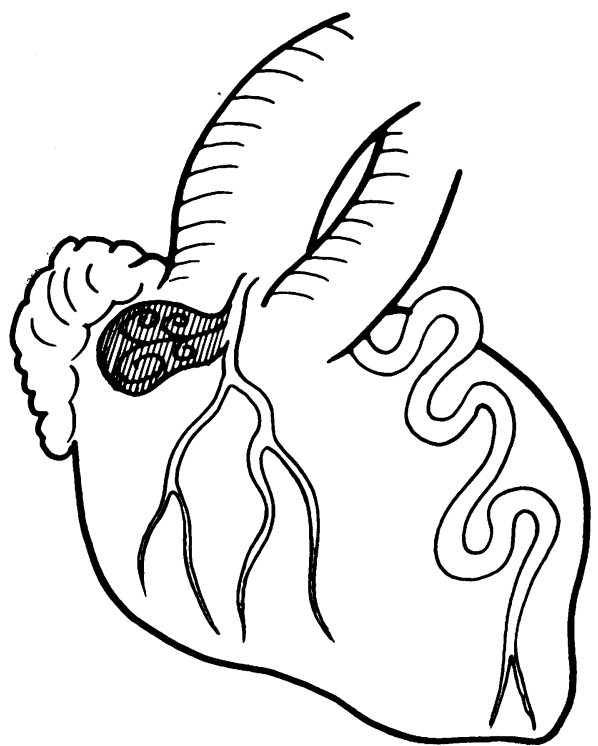

Fig. 6.-Case 2. Diagrammatic illustration: aneurysm of the right coronary artery, tortuous left coronary artery.

\section{Discussion}

In the literature of the last century we already find a few reports of similar cases (Brooks, 1886; and those of the following authors cited by Packard and Wechsler (1929): Peste, 1843; Peacock, 1846-48, 1849; Wood, 1860; Büchner, 1867; Gee, 1871; Crisp, 1871; Malet and Evans, 1887; Capps, 1899). Packard and Wechsler collected 30 cases with localized aneurysms of the coronary arteries, most of them being arteriosclerotic or mycotic in origin. These authors did not consider the possibility of congenital origin in their cases. Scott (1948), in reviewing the literature recorded a total of 48 cases, including the 30 cases mentioned by Packard and Wechsler. Ten of these cases Scott attributed to congenital anomalies. In most of them, however, the investigations were rather poor and therefore they will be omitted here. Scott himself collected 10 cases with congenital aneurysms, five of which were localized and five diffuse forms. In the others the aneurysms were thought to be acquired during later life. One of these cases (Trevor, 1912) enumerated by Scott together with the mycoticembolic aneurysms we shall add to the congenital

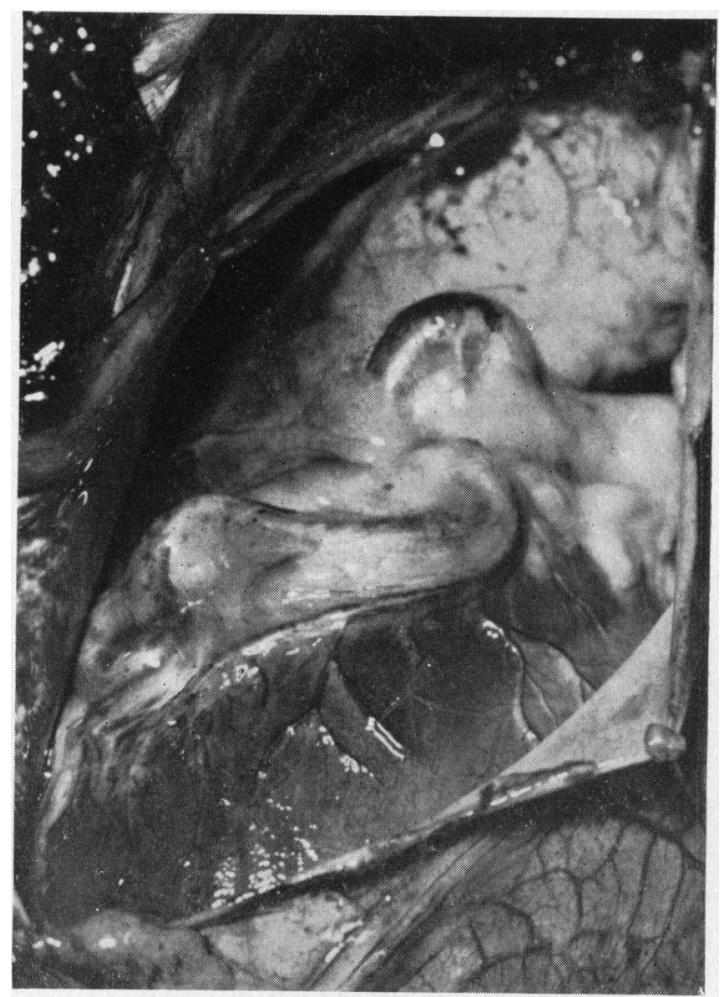

FIG. 7.-Case 2. Finding at operation: cirsoid dilatation of the left coronary artery. 
aneurysms, as it presented convincing features of a congenital malformation of the coronary arteries.

Since Scott's review 21 cases of congenital aneurysms of the coronary arteries have been published, most of them showing an abnormal communication with other parts of the heart (cf. Brown and Burnett, 1949; Paul, Sweet and White, 1949; Gross, personal communication; Espino Vela, Velazquez and Fuenmayor, 1951; Baylis and Campbell, 1952; Colbeck and Shaw, 1954; Lovitt and Lutz, 1954; Davison, McCracken and McIlveen, 1955; Sondergaard, 1955; Davis, Dillon, Fell and Gasul, 1956; Knoblich and Rawson, 1956; Mozen, 1956; Apley, Horton and Wilson, 1957; Michel and Herbst, 1957; Walther, Starkey, Zervopolus and Gibbons, 1957; Edwards, Gladding and Weir, 1958; Steinberg, Baldwin and Dotter, 1958; Garomella, personal communication; Gasul, Fell and Dillon, personal communication; Morrow, personal communication). Furthermore we found four other cases reported before this review which Scott did not consider (Blakeway, 1918; Björk and Crafoord, 1947; Emminger, 1947; Valdivia, Rowe and Angevine, 1947). They raise the number of accounts of congenital aneurysms published in the last 50 years to 36 .

$\mathrm{Up}$ to recent years the malformation in question was detected only at autopsy and was more or less of academic interest. Today cardiological investigations are able to detect the condition during life and to select the cases amenable to surgery. In a few cases the condition was discovered by chance at thoracotomy. At an operation performed for suspected patent ductus Björk and Crafoord (1947) discovered an aneurysm of the left coronary artery with a fistula to the pulmonary artery. Ligation of both the ductus and the coronary fistula was successful. Since that time there have been several case reports (Gross, personal communication; Sondergaard, 1955; Mozen, 1956; Davis, Dillon, Fell and Gasul, 1956; Walther, Starkey, Zervopolus and Gibbons, 1957) in which the diagnosis of suspected ductus led to thoracotomy. But in all these cases instead of the expected ductus, a fistulous communication between the coronary vessels and other parts of the heart was found.

In the case of Michel and Herbst (1957) a large fistula between an anomalous coronary artery and the pulmonary conus was discovered at an operation performed on a child with tetralogy of Fallot. Clamping of this vessel caused cardiac arrest, and therefore surgery was restricted to valvulotomy of the pulmonary artery.

In a patient with a continuous murmur over the heart Walther et al. (1957) were able to withdraw highly oxygenated blood out of the middle cardiac vein during cardiac catheterization. On the strength of this finding Walther assumed the presence of a communication between the coronary vein and a coronary artery.

In the absence of surgical intervention, however, diagnosis can only be established by angiocardiography. In Steinberg, Baldwin and Dotter's (1958) case, venous angiocardiography revealed a cluster of large coiled vessels below the left ventricle. Similarly in the case of Gasul, Fell and Dillon an aneurysm of the right coronary artery was demonstrated by contrast visualization, and at least in our first case the same technique was used with success.

Another possibility of roentgenologic investigation is offered by retrograde aortography. By means of this technique Morrow was able to demonstrate an anomalous communication between the aorta and the right atrium. Surgical exploration identified the suspected coronary aneurysm with an arteriovenous fistula, which could be closed at its right atrial aspect.

Pathological features in the 36 cases published during the last 50 years consisted either in localized, saccular, or in diffuse dilatations, involving the right coronary artery in 19 cases, the left in 15 cases; in one case both the right and the left coronary artery was affected (Rigden and Vandergriff, 1943) and in one localization was not specified (Walther et al., 1957). In 32 cases a communication to other parts of the heart was demonstrated, in 10 to the right ventricle, in six to the pulmonary artery, in five to the right atrium, in four to the coronary sinus, in four to a coronary vein, in two to the left ventricle, and in one to the left atrium. The fistulous communication may be small and therefore overlooked. In the cases without any fistula, the aneurysmal dilatation may be the result of congenital defects involving especially the elastic tissue of these vessels (Forbus, 1930; Lepow, Chu and Muren, 1958).

Coronary aneurysms with fistulous connexion to the cardiac chambers or other structures of the heart have been explained aetiologically on the basis of the embryological studies by Grant and Viko (1929).

The myocardial vessels are derived from two sources. In the first foetal period blood supply to the myocardium is furnished by endothelial-lined channels protruding from the ventricular cavity into the intermuscular spaces, forming a vascular network. The other source is derived from the coronary arteries and veins growing as buds out of the truncus arteriosus and the sinus venosus during the second to the fourth week of foetal life, at the same time as the aorto-pulmonary septum is 
beginning to develop. First, the coronary arteries and veins expand at the surface of the myocardium to join later the intertrabecular blood spaces. Gradually this vascular network develops into capillaries, some of them, however, retaining larger communications with the ventricular cavities, known as the Thebesian orifices of the adult heart. These openings may have a diameter up to $1 \mathrm{~mm}$.

Abnormal development of the vascular system may occur at different stages and involve different parts of the myocardial vessels. Abnormal localization of the buds of the coronary arteries at the common trunk will result in anomalous origin of these vessels, i.e. from the pulmonary artery. If the narrowing of the intermuscular blood spaces fails, sponge-like sinusoids in the myocardial wall, with large communications both with the coronary vessels and with the cardiac cavities, will persist (Wilson and Grant, 1926 ; Grant, 1926). If disturbance of regression is limited to one Thebesian vessel, an isolated fistula between the coronary arteries and the cardiac chambers will be the result. Blood flow from the high to the low pressure system will be increased and therefore dilatation of the affected vessel becomes more and more marked in the course of time. Given sufficient shunt-volume action over a long period of time, ventricular hypertrophy and heart failure are inevitable. In addition, blood supply to the myocardium in the area of the fistula will be decreased, as the fistulous vessel derives blood from the branches connected with it. This fact is proved by electrocardiographic tracings as well as by histological examinations of the myocardium, which in some cases exhibits signs of ischaemic injury.

The malformation, however, need not result in functional disability, especially not during pregnancy. Generally a murmur over the heart, detected by chance, is the reason for cardiac investigations. In cases with a coronary fistula a continuous murmur similar to the finding in patent ductus may be present, especially if the fistula leads to the pulmonary trunk. The site of maximal intensity, however, mostly differs from the finding in patent ductus, as it depends on the localization of the aneurysm. Therefore it may be heard best lower at the sternal border, on the sternum or even at its right margin. In phonocardiographic tracings, maximal amplitude of the continuous murmur does not occur together with the second heart sound as in Botallo's duct, but in the middle or late diastole.

Two other lesions capable of producing similar murmurs play a part in differential diagnosis : a ruptured aneurysm of the sinus of Valsalva and an aortico-pulmonary septal defect. Although cardiac catheterization may reveal the presence of a left-toright shunt, correct non-surgical diagnosis with exclusion of other lesions accompanying shunt, is possible only with the help of angiocardiography or aortography as proved by our first case and the reports of Steinberg et al. (1958), Gasul et al. (personal communication), and Morrow (personal communication).

\section{Summary}

Two cases of aneurysms of the coronary arteries are reported. In the first case the aneurysm was localized at the left coronary artery, in the second both the right and the left coronary artery were affected.

Thirty-six cases in the literature of the last 50 years are collected, whose pathological features are summarized. In most of the cases diagnosis was established only at autopsy, and in some cases published during the last few years at thoracotomy, which was mostly performed for suspected ductus arteriosus. It must be assumed that this malformation occurs more frequently than is commonly believed.

As in many cases the main clinical finding consists of a continuous murmur over the heart, the presence of a coronary aneurysm should be taken into account simultaneously with other conditions causing a continuous murmur, especially if the localization of the murmur is unusual.

It is pointed out that modern cardiac investigations, above all angiocardiography, are able to establish a correct non-surgical diagnosis, which is illustrated by the first case reported herein.

\section{REFERENCES}

Apley, J., Horton, R. E. and Wilson, M. G. (1957). Thorax, 12, 28. Baylis, J. H. and Campbell, M. (1952). Guy's Hosp. Rep., 101, 174. Björk, G. and Crafoord, C. (1947). Thorax, 2, 65.

Blakeway, H. (1918). J. Anat. (Lond.), 52, 354.

Brooks, H. St. John (1886). Ibid., 20, 26.

Brown, R. C. and Burnett, J. D.' (1949). Pediatrics, 3, 597.

Büchner (1867). (Cited by Packard and Wechsler.) Aneurysma der Arteria coronaria cordis sinistra. Vander Post, Amsterdam.

Capps, J. A. (1899). (Cited by Packard and Wechsler.) Amer. J. med. Sci., 118, 312 .

Colbeck, J. C. and Shaw, J. M. (1954). Amer. Heart J., 48, 270.

Crisp, E. (1871) (Cited by Packard and Wechsler.) Trans. path. Soc. Lond., 22, 106.

Davison, P. H., McCracken, B. H. and Mcllveen, D. J. S. (1955). Brit. Heart J., 17, 569 .

Edwards, J. E., Gladding, T. C. and Weir, A. B. (1958). J. thorac. Surg., 35, 662.

Emminger, E. (1947). Klin. Med. (Wien), 2, 652.

Espino Vela, J., Velazquez, T. and Fuenmayor, A. (1951). (Cited by Edwards et al.) Arch. Inst. Cardiol. Méx., 21, 686.

Forbus, W. D. (1930). Bull. Johns Hopk. Hosp., 47, 239.

Garomella, J. J. Personal communication. (C̈ited by Edwards et al.)

Gasul, B. M., Fell, E. H. and Dillon, R. F. Personal communication. (Cited by Edwards et al.)

Gee, S. J. (1871). (Cited by Packard and Wechsler.) St Bart's Hosp. Rep., 7, 148.

Grant, R. T. (1926). Heart, 13, 273.
and Viko, L. E. (1929). Ibid., 15, 103. 
Gross, R. E. Personal communication. (Cited by Paul et al.) Knoblich, R. and Rawson, A. J. (1956). Amer. Heart J., 52, 474. Lepow, H., Chu, F. and Muren, O. (1958). Amer. J. Med., 24, 631. Lovitt, W. V. Jr. and Lutz, S. (1954). A.M.A. Arch. Path. 57, 163 Malet and Evans, A. (1887). (Cited by Packard and Wechsler.) Lancet, 2, 67.

Michel, D. and Herbst, M. (1957). Z. Kreisl.-Forsch., 46, 538.

Morrow, A. G. Personal communication. (Cited by Ëdwards et al.)

Mozen, H. E. (1956). Ann. Surg., 144, 215.

Packard, M. and Wechsler, H. F. (1929). Arch. intern. Med., 43, 1.

Paul, O. Sweet, R. H. and White, P. D. (1949). Amer. Heart J. Paul, O., Sweet,

Peacock (1846-48). (Cited by Packard and Wechsler.) Trans, path. Soc. Lond., 1, 227.

- (1849). (Cited by Packard and Wechsler.) Ibid., 9, 592.

Peste (1843). (Cited by Packard and Wechsler.)
Rigdon, R. H. and Vandergriff, H. (1943). Amer. J. Surg., 61, 407.

Scott, D. H. (1948). Amer. Heart J., 36, 403.

Sondergaard, T. (1955). In Henry Ford Hospital International Symposium on Cardiovascular Surgery, ed. C. R. Lam, p. 490. Saunders, Philadelphia.

Steinberg, I., Baldwin, J. S. and Dotter, C. T. (1958). Circulation, 17, 372 .

Trevor, R. S. (1911-12). Proc. roy. Soc. Med., 5, pt. 1 (section for the study of disease in children), p. 20

Valdivia, E., Rowe, G. G. and Angevine, D. M. (1957). Arch. Path. (Chicago), 63, 168.

Walther, R. J., Starkey, G. W. B., Zervopolus, E. and Gibbons,

G. A. (1957). Amer. J. Med., 22, 213.

Wood (1860). (Cited by Packard and Wechsler.) N.Y. med. J., 